\title{
Involvement of the Plant Polymer Suberin and the Disaccharide Cellobiose in Triggering Thaxtomin A Biosynthesis, a Phytotoxin Produced by the Pathogenic Agent Streptomyces scabies
}

\author{
Sylvain Lerat, Anne-Marie Simao-Beaunoir, Run Wu, Nathalie Beaudoin, and Carole Beaulieu
}

Centre SÈVE, Département de biologie, Université de Sherbrooke, Sherbrooke, Québec J1K 2R1, Canada.

Accepted for publication 14 September 2009.

\begin{abstract}
Lerat, S., Simao-Beaunoir, A.-M., Wu, R., Beaudoin, N., and Beaulieu, C. 2010. Involvement of the plant polymer suberin and the disaccharide cellobiose in triggering thaxtomin A biosynthesis, a phytotoxin produced by the pathogenic agent Streptomyces scabies. Phytopathology 100: 91-96.

Streptomyces scabies is a gram-positive soil bacterium recognized as the main causal agent of common scab. Pathogenicity in Streptomyces spp. depends on their capacity to synthesize phytotoxins called thaxtomins. Genes involved in biosynthesis of these secondary metabolites are known to be induced by cellobiose, a plant disaccharide. However, growth of $S$. scabies in a minimal medium containing cellobiose as a

carbon source is very poor and only generates traces of thaxtomins. The effect of suberin, a lipid plant polymer, on thaxtomin A biosynthesis and the expression of genes involved in its biosynthetic pathway was analyzed. S. scabies was grown in a starch-containing minimal medium supplemented with cellobiose $(0.5 \%)$, suberin $(0.1 \%)$, or both. The presence of both cellobiose and suberin doubled bacterial growth and triggered thaxtomin A production, which correlated with the upregulation (up to 342-fold) of genes involved in thaxtomins synthesis. The addition of either suberin or cellobiose alone did not affect these parameters. Suberin appeared to stimulate the onset of secondary metabolism, which is a prerequisite to the production of molecules such as thaxtomin A, while cellobiose induced the biosynthesis of this secondary metabolite.
\end{abstract}

Streptomycetes are soil bacteria known for their ability to produce a large array of secondary metabolites. Most species belonging to the genus Streptomyces are strictly saprophytic microorganisms. However, a small number of species can also thrive as phytopathogenic agents. One of them is Streptomyces scabies (or scabiei), recognized worldwide as the main causal agent of common scab. Symptoms of common scab vary from corky patches to deep-pitted lesions on the surface of tubers or root vegetables such as potato, radish, carrot, and turnip (8). The development of this disease in the field often results in substantial economic losses for growers (11).

The ability of common scab-causing agents to affect their hosts depends on their capacity to produce phytotoxins called thaxtomins. Thaxtomins are secondary metabolites synthesized after cyclization and modification of both a tryptophan and a phenylalanine molecule. In S. scabies, the major form of thaxtomin produced is thaxtomin A (19). Conditions that trigger thaxtomin synthesis in $S$. scabies are progressively being elucidated. Under laboratory conditions, oat bran broth has been recognized as an excellent thaxtomin-inducing medium and has been widely used for the purpose of generating large amounts of thaxtomins $(9,16)$. However, this medium is particularly rich in carbohydrates and plant-derived compounds and, therefore, this high complexity renders identification of thaxtomin inducers difficult.

Corresponding author: C. Beaulieu;

E-mail address: carole.beaulieu@usherbrooke.ca

* The $\boldsymbol{e}$-Xtra logo stands for "electronic extra" and indicates that the online version contains a table showing suberin-derived molecules tested for the induction of thaxtomin A in S. scabies EF-35 and a figure showing cellobiose uptake in $S$. scabies EF-35 grown in the absence or presence of suberin. Figure 4 appears in color online.

doi:10.1094/PHYTO-100-1-0091

(C) 2010 The American Phytopathological Society
In a study where the effect of diverse plant extracts on thaxtomin A production was tested in three $S$. scabies strains, phytotoxin synthesis was slightly induced when a minimal growth medium was supplemented with suberin (1), a complex plant polymer found on the surface of potato tubers and characterized by the presence of aliphatic and phenolic domains (2). In a recent study, cellobiose, a plant disaccharide resulting from the hydrolysis of cellulose, was identified as an inducer of thaxtomin A synthesis in S. scabies (12).

In this article, the involvement of both suberin and cellobiose in the elicitation of thaxtomin A synthesis by S. scabies strain EF-35 was further investigated. Weak induction of thaxtomin A biosynthesis was detected in culture media containing cellobiose or suberin. However, the toxin biosynthesis was considerably increased in the presence of both cellobiose and suberin in the culture medium. Possible mechanisms underlying the role of suberin in thaxtomin biosynthesis are proposed.

\section{MATERIALS AND METHODS}

Bacterial cultivation and growth conditions. S. scabies strain EF-35 (7) was used in this study. All experiments were performed in liquid media, with the exception of morphological assays, which were conducted on petri dishes (see below). S. scabies spores $\left(10 \mu \mathrm{l}, \approx 10^{8}\right.$ spores) were inoculated into $25 \mathrm{ml}$ of tryptic soy broth (TSB) and grown on a rotary shaker $(250 \mathrm{rpm})$ at $30^{\circ} \mathrm{C}$ for $48 \mathrm{~h}$. Bacteria were then centrifuged $(10 \mathrm{~min}$ at $3,450 \times \mathrm{g})$ and resuspended in 5 volumes of fresh TSB (9). Then, 50 or $100 \mu$ of this suspension were used to inoculate flasks containing 25 or $50 \mathrm{ml}$ of minimal starch medium, respectively. Minimum starch medium (MSM) consisted of $0.5 \%$ (wt/vol) starch, asparagine at $0.5 \mathrm{~g} \mathrm{liter}^{-1}, \mathrm{~K}_{2} \mathrm{HPO}_{4}$ at $0.5 \mathrm{~g} \mathrm{liter}^{-1}, \mathrm{MgSO}_{4}$ at $0.2 \mathrm{~g} \mathrm{liter}^{-1}$, and $\mathrm{FeSO}_{4}-7 \mathrm{H}_{2} \mathrm{O}$ at $5 \mathrm{mg}$ liter ${ }^{-1}$. This medium was supplemented by one or two additional carbon sources: $0.5 \%$ (wt/vol) cellobiose (Sigma-Aldrich, St. Louis, MO) and $0.1 \%$ (wt/vol) suberin. 
Suberin was purified from potato (cv. Russet) peels according to the method described by Kolattukudy and Agrawal (17).

Biomass and thaxtomin A production. The effect of growth medium on both biomass and thaxtomin A production was determined 6 days after inoculation. Bacterial cultures $(25 \mathrm{ml})$ were centrifuged for $10 \mathrm{~min}$ at $3,450 \times g$. Supernatants were decanted and used for thaxtomin A quantification. Pellets (containing bacteria and insoluble suberin) were dried for $24 \mathrm{~h}$ at $50^{\circ} \mathrm{C}$ and weighed. Previous auxiliary experiments showed that suberin weight was not noticeably modified throughout the experiment (unpublished data). Consequently, in suberin-containing treatments, bacterial growth was determined after deduction of the initial suberin weight $(25 \mathrm{mg})$ from the recorded dry weights. Purification and quantification of thaxtomin $\mathrm{A}$ in supernatants were carried out according to Goyer et al. (9) with slight modifications. Briefly, organic molecules were extracted from the supernatant using ethyl acetate, concentrated in $1.5-\mathrm{ml}$ tubes, and dried by evaporation. The extracted molecules were migrated on thin-layer chromatography using chloroform/ methanol (9:1). Thaxtomin A ( $R f$ 0.27) was eluted with chloroform/methanol (7:3), dried, suspended in $1 \mathrm{ml}$ of acetonitrile, and quantified by high-performance liquid chromatography at $249 \mathrm{~nm}$, performing elution with a 25 to $75 \%$ acetonitrile gradient for 10 min at a flow rate of $1.3 \mathrm{ml} \mathrm{min}{ }^{-1}$. Thaxtomin A amounts were determined using a standard curve constructed using known quantities of purified thaxtomin A.

Quantitative real-time polymerase chain reaction. The expression of genes involved in thaxtomin A biosynthesis and cellobiose assimilation (transport and hydrolysis) was investigated. Blast analysis against the $S$. scabies strain 87.22 genome sequence (Sanger Institute, http://www.sanger.ac.uk/Projects/ S_scabies/) was performed to identify DNA regions exhibiting similarities with protein sequences of cellobiose transporters and cellobiose hydrolases (cellobiases) characterized in the genus Streptomyces. The complete corresponding coding sequence (CDS) was predicted using the GeneMarkHMM for Prokaryotes (version 2.4) program. Amino-acid sequences deduced from the CDS were then compared by Blast analysis against the National Center for Biotechnology Information protein database to confirm that their putative protein functions corresponded to cellobiose transporters and cellobiases. Sequences of two genes involved in thaxtomins biosynthesis in S. acidiscabies, nos and txtA $(10,15)$, showed $100 \%$ similarity with sequences in $S$. scabies. Genes under study, as well as their primer pairs suitable for quantitative real-time polymerase chain reaction (PCR), are listed in Table 1.
Bacterial inoculum was added to flasks containing $50 \mathrm{ml}$ of growth medium (three replicates per treatment). Subsamples $(10 \mathrm{ml}$ each) were collected $24 \mathrm{~h}$ after inoculation and 5-ml subsamples were collected at 48 and $72 \mathrm{~h}$. Stop solution (0.2 volume ethanol/acidic phenol, 95:5) (13) was immediately added to these subsamples to prevent RNA degradation. Total RNA extraction was carried out using the Qiagen RNeasy mini kit (Qiagen, Valencia, CA) with the following modifications. Cell lysis was completed by sonication of bacterial suspension $(3 \times$ $20 \mathrm{~s}$ ). Cell debris was then eliminated by standard washes with 2 volumes of acidic phenol/chloroform (1:1) (twice) and chloroform. On-column degradation of genomic DNA was achieved with Turbo DNA-free (Ambion, Austin, TX). Reverse transcription was performed on $2 \mu \mathrm{g}$ of total RNA using the First strand cDNA synthesis kit (GE Healthcare, Buckinghamshire, UK) and $72 \%$ G+C-rich random hexamers. Real-time PCR was performed with $2 \mu \mathrm{l}$ (in a final volume of $20 \mu \mathrm{l}$ ) of $10 \times$ diluted cDNA. PCR conditions were $95^{\circ} \mathrm{C}$ for $3 \mathrm{~min}$ followed by 35 cycles at $95^{\circ} \mathrm{C}$ for $15 \mathrm{~s}$ and $60^{\circ} \mathrm{C}$ for $45 \mathrm{~s}$. The absence of genomic DNA was verified in samples ( $2 \mu \mathrm{g}$ of total RNA) where reverse transcriptase was omitted in the cDNA synthesis reaction. Relative gene expression was calculated according to Pfaffl (23) using gyrA as the reference gene (13).

Quantification of cellobiose uptake. The capacity of bacteria to utilize cellobiose was assessed. Cellobiose uptake was quantified by depletion in the growth medium of bacteria grown in the absence or presence of suberin as follows. Cellobiose-added MSM (50 ml) was supplemented or not with suberin and inoculated as described above. In order to collect suberin-free bacteria, suberin was placed in $\approx 1.5$-by- 1.5 -cm cotton pouches prior to sterilization. Empty cotton pouches were added to the starch- and cellobiose-containing MSM. After $48 \mathrm{~h}$ of growth, bacterial cultures were transferred to sterile 50-ml tubes and centrifuged for $5 \mathrm{~min}$. Bacterial pellets were rinsed twice with 2.5 volumes of fresh minimal medium, and $4 \mathrm{ml}$ of bacterial suspension (from the bottom of the tubes) was transferred to new tubes. After a 5-min centrifugation, supernatants were discarded and bacterial fresh weights were recorded to ensure that quantities of bacteria transferred were similar among treatments and replications. Pellets were then resuspended in $50 \mathrm{ml}$ of minimal medium containing $0.5 \%$ cellobiose as sole source of carbon and transferred to new flasks. Growth medium $(100 \mu \mathrm{l})$ was taken 24 , 48 , and $72 \mathrm{~h}$ after transfer and remaining cellobiose content was determined using the reducing sugars method (20).

Growth on solid medium. The morphological aspect of bacterial colonies grown in the presence or absence of cellobiose

TABLE 1 . Genes targeted for relative quantification of transcripts and primer sequences used in this study

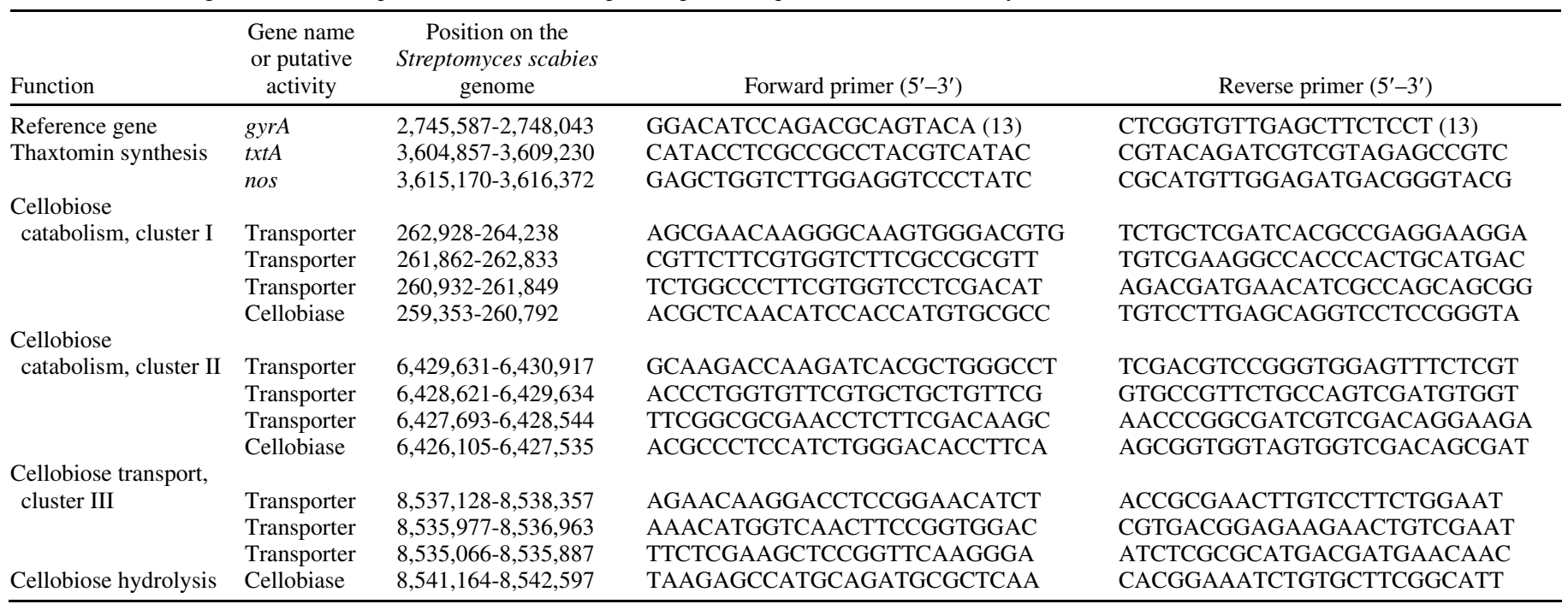


or suberin was observed on solid medium. Approximately 100 spores of $S$. scabies EF-35 were plated on petri dishes containing the four different solidified (agar at $15 \mathrm{~g} \mathrm{liter}^{-1}$ ) growth media at the usual concentrations (see growth conditions). Petri dishes were incubated at $30^{\circ} \mathrm{C}$. Five days after inoculation, representative colonies of each treatment were photographed at a $\times 20$ magnification.

Statistical analyses. Experiments were repeated three times in three independent replicates. Statistical analyses were carried out using the GLM procedure of the SAS 9.1 statistical package. All sets of data requiring statistical analyses were performed with two-way analysis of variance (ANOVA) with growth medium (treatment) and repetition as main factors. A posteriori comparisons were made using least significant difference tests.

\section{RESULTS}

Biomass and thaxtomin A production. The ANOVA revealed a strong medium (treatment) effect but also variability between repeats $(P<0.05)$. However, statistical analyses of the different repetitions taken separately (one-way ANOVA) generated analogous significant differences among treatments. Consequently, results of one repetition are here presented but are representative of a general pattern. After 6 days of growth, bacterial dry weight of $S$. scabies EF-35 doubled when both cellobiose and suberin were present in a MSM $(P=0.0006)$ (Table 2). However, the addition of either suberin or cellobiose to an MSM did not significantly alter bacterial dry weight. Furthermore, the production of thaxtomin A was strongly stimulated when cellobiose and suberin were combined in the MSM $(P<0.0001)$ (Table 2$)$. No thaxtomin A was detected in the MSM whereas only trace amounts were quantified when this growth medium was supplemented with either suberin or cellobiose alone.

The combination of suberin and cellobiose strongly stimulated thaxtomin A production; therefore, dose-response curves were performed to determine what were the optimal cellobiose and suberin concentrations to induce the highest production of thaxtomin A (Fig. 1). The lowest cellobiose concentration tested that significantly induced thaxtomin A production (in the presence of $0.1 \%$ suberin) was $0.25 \%$ (Fig. $1 \mathrm{~A}$ ) whereas the lowest suberin concentration tested that significantly induced the toxin production (in the presence of $0.5 \%$ cellobiose) was $0.05 \%$ (Fig. 1B). Maximum thaxtomin A production were reached at $0.5 \%$ cellobiose and at $0.1 \%$ suberin. Therefore, in accordance with the present results, these concentrations are now routinely used to induce thaxtomin production.

Gene expression. The analysis of variance revealed strong medium effects but also several significant repetition effects and significant medium-repetition interactions $(P<0.05)$. However, statistical analyses of the different repetitions taken separately (one-way ANOVA) generated similar outcomes. Therefore, results of one representative repetition are presented. The expression of the genes involved in thaxtomin synthesis was strongly induced by the presence of both cellobiose and suberin, when compared

TABLE 2. Bacterial growth and thaxtomin A production ( \pm standard deviation) of Streptomyces scabies EF-35 grown for 6 days in minimal medium (+ starch $0.5 \%$ ) not supplemented (negative control) or supplemented with suberin, cellobiose, or both ${ }^{\mathrm{z}}$

\begin{tabular}{lcc}
\hline Medium supplement & $\begin{array}{c}\text { Bacterial dry } \\
\text { weight }(\mathrm{mg})\end{array}$ & $\begin{array}{c}\text { Thaxtomin A production } \\
\left.(\mu \mathrm{g} \mathrm{mg} \mathrm{bacteria})^{-1}\right)\end{array}$ \\
\hline Negative control & $27.7 \pm 9.5 \mathrm{a}$ & Not detected a \\
Suberin $0.1 \%$ & $35.9 \pm 5.6 \mathrm{a}$ & $0.03 \pm 0.01 \mathrm{a}$ \\
Cellobiose $0.5 \%$ & $27.1 \pm 1.9 \mathrm{a}$ & $<0.01 \pm 0.01 \mathrm{a}$ \\
Cellobiose $0.5 \%+$ suberin $0.1 \%$ & $56.7 \pm 0.7 \mathrm{~b}$ & $2.08 \pm 0.39 \mathrm{~b}$ \\
\hline
\end{tabular}

${ }_{\mathrm{z}}$ Values within a column with the same letter are not significantly different (least significant difference test). with the nonsupplemented starch treatment, at 24, 48, and $72 \mathrm{~h}$ (Fig. 2). Maximal expression was observed at $72 \mathrm{~h}$; the nos and txtA genes were upregulated by 229 - and 342 -fold, respectively. On the other hand, the presence of either suberin or cellobiose alone in the MSM did not stimulate expression of these genes.

Twelve open reading frames coding for genes potentially involved in cellobiose uptake and cellobiose hydrolysis were identified in the genome of S. scabies. They fall in three clusters, named from I to III according to their position on the genome (Table 1). No gene expression was detected for the three putative cellobiose transporters of cluster III and their neighboring putative cellobiase. Conversely, the expression of genes of clusters I and II was altered by treatment, with more remarkable variations for genes of cluster II. Only the relative expressions of genes in cluster II are presented (Fig. 3). These genes were strongly induced (up to 1,200-fold for the cellobiase-like gene at $24 \mathrm{~h}$ ) in bacteria grown in the cellobiose-containing treatments at all sampling times (Fig. 3). The presence of cellobiose alone often significantly increased expression of cluster II genes but the addition of suberin significantly enhanced the inducing effect of cellobiose (Fig. 3). The presence of suberin alone did not induce significant gene expression increases.

Cellobiose uptake. Bacterial cells exposed or not to suberin in cellobiose-containing MSM for $48 \mathrm{~h}$ were transferred to minimal medium supplemented with cellobiose $(0.5 \%)$ only. Both groups of cells utilized cellobiose at the same rate at all times tested.

Cellobiose and suberin affect the morphology of $S$. scabies colonies on solid medium. Five days after inoculation, bacteria
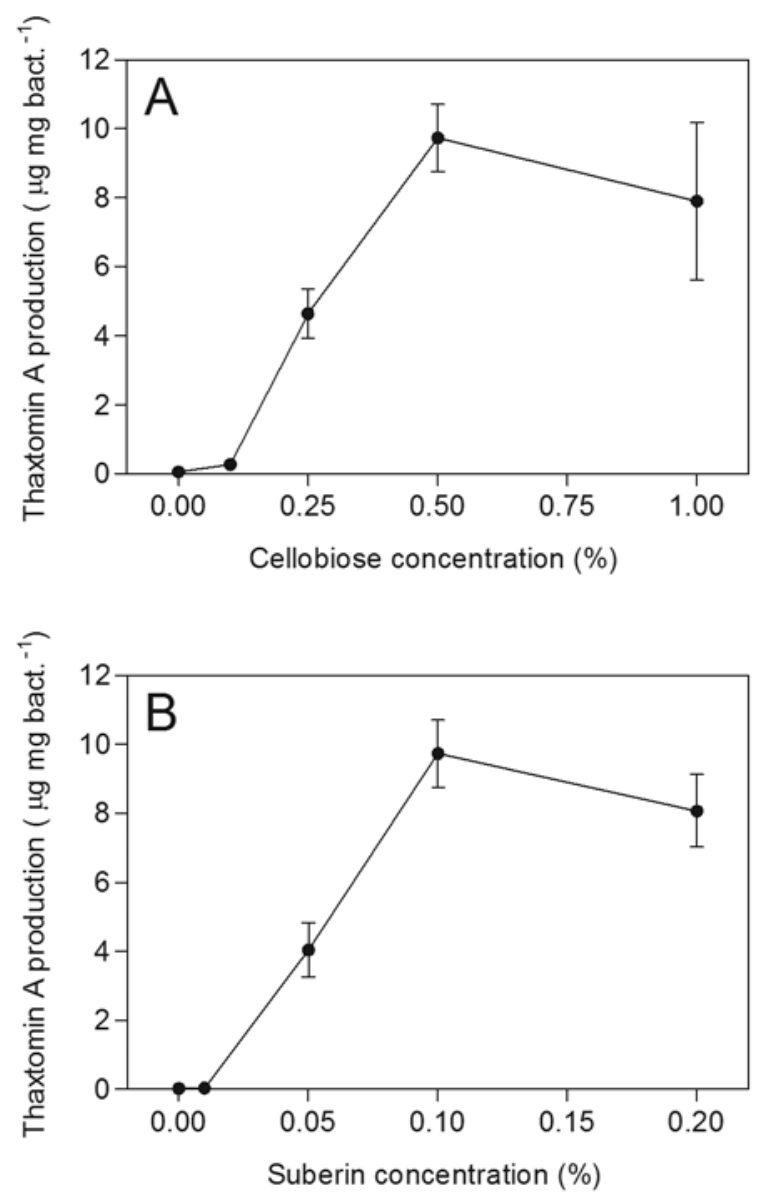

Fig. 1. Thaxtomin A production ( \pm standard deviation) by Streptomyces scabies EF-35 after 6 days of growth in minimum starch medium as a function of cellobiose and suberin concentrations. A, Increasing cellobiose concentrations $(0,0.1,0.25,0.5$, and $1 \%)$ were tested with constant suberin concentration $(0.1 \%)$. B, Increasing suberin concentrations $(0,0.01,0.05,0.1$, and $0.2 \%$ ) were tested with constant cellobiose concentration $(0.5 \%)$. 
grown on MSM (starch-containing control treatment) formed colonies exhibiting moderate aerial mycelium development (Fig. 4A). In the presence of cellobiose and in the absence of suberin, colonies appeared bald because no or extremely weak aerial growth was observed (Fig. 4C). Further experiments revealed that bald colonies were observed for cellobiose concentrations $>0.1 \%$ (data not shown). The presence of suberin generated larger colonies with a very pronounced convex shape (Fig. 4B and D). Colonies grown in the presence of suberin alone appeared completely white, denoting an important development of aerial mycelium. In colonies grown on MSM supplemented with both cellobiose and suberin, aerial growth was scarce and visible mostly at the edge of the colonies.

\section{DISCUSSION}

Thaxtomins are synthesized during the characteristic secondary growth phase of pathogenic streptomycetes. In streptomycetes, the onset of secondary metabolism and the transition phase from vegetative growth to the stationary phase depends on various molecular signals, including guanoside nucleotides (4), branchedchain amino acids (27), and extracellular oligopeptides recog-
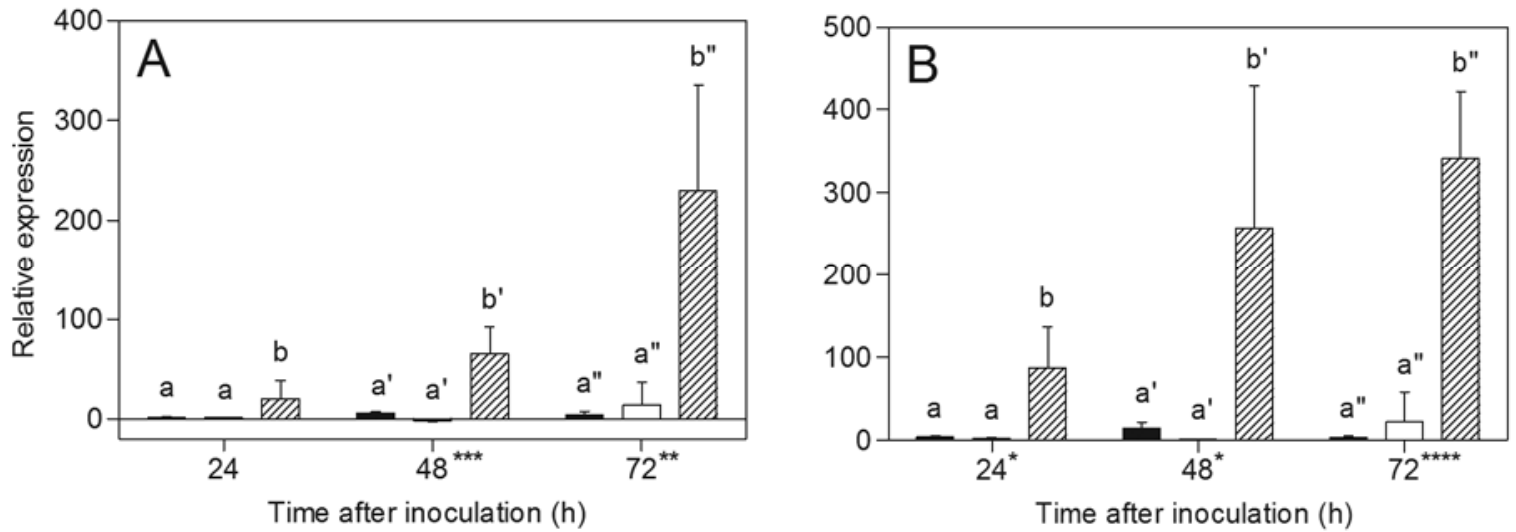

Fig. 2. Relative expression levels ( \pm standard deviation) of the $\mathbf{A}$, nos and $\mathbf{B}$, txtA genes involved in thaxtomin biosynthesis in Streptomyces scabies EF-35 grown in the presence of $0.1 \%$ suberin (black bars), $0.5 \%$ cellobiose (white bars), or suberin + cellobiose (hatched bars) compared with nonsupplemented minimal starch medium 24, 48, and $72 \mathrm{~h}$ after inoculation. Data were normalized with the gyrA gene used as internal control. Data shown are representative of three independent experiments performed in triplicates; $*^{* *}, * * *$, and $* * * *$ indicate $P<0.05,0.01,0.001$, and 0.0001 , respectively. Data within a time with the same letter are not statistically different (least significant difference test, control $=a$ ).
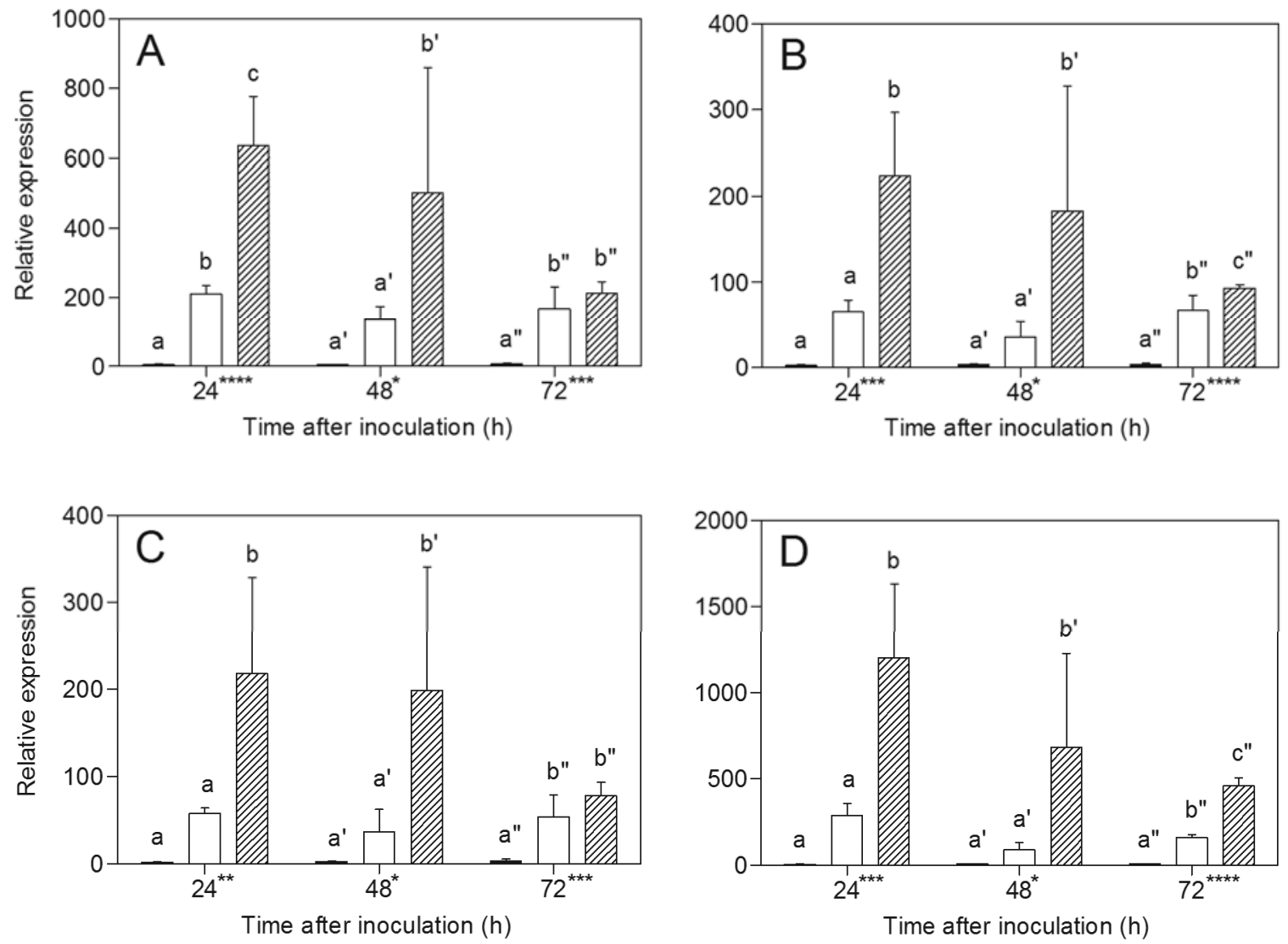

Fig. 3. Relative expression levels ( \pm standard deviation) of four clustered genes putatively involved in cellobiose assimilation in Streptomyces scabies EF-35. A, B, and $\mathbf{C}$, Three cellobiose transporter-like genes and $\mathbf{D}$, one cellobiase-like gene were targeted in bacteria grown in the presence of $0.1 \%$ suberin (black bars), $0.5 \%$ cellobiose (white bars), or suberin + cellobiose (hatched bars) compared with nonsupplemented minimal starch medium 24,48 , and $72 \mathrm{~h}$ after inoculation. Data were normalized with the gyrA gene used as internal control. Symbols and lettering with regard to statistical tests are as in Figure 1. 
nized by BldK proteins (22). A previous proteomic differential display technique used to study the cellular responses of $S$. scabies exposed to suberin revealed that enzymes involved in the biosynthesis or the transport of these signal molecules were differentially produced in response to suberin (18). Furthermore, in the present article, aerial mycelium development appeared to be stimulated in the presence of this plant polymer, as seen in Figure 4. Thus, suberin appears to interfere with the onset or the progression of secondary metabolism in S. scabies.

The role of cellobiose as an inducer of thaxtomin A biosynthesis was initially demonstrated in S. acidiscabies (28) whereas the addition of suberin to minimal medium was shown to generate moderate production of the toxin in several S. scabies strains (1). Very poor bacterial growth was observed when $S$. scabies was grown on suberin (1) or cellobiose (28) as the sole carbon source. In the present experiments, proper bacterial growth was ensured by the addition of starch to the growth media. No significant difference in biomass production was found between starch medium, starch and suberin medium, and starch and cellobiose medium, suggesting again that cellobiose and suberin are, by themselves, poor growth substrates for $S$. scabies. When $S$. scabies was grown in an MSM supplemented with both cellobiose and suberin, the final bacterial dry weight approximately doubled, suggesting a synergetic effect of suberin and cellobiose on bacterial growth.

Because suberin is known as a membrane-perturbing substance (6), the hypothesis that suberin could facilitate cellobiose uptake and, thus, would explain the better growth of S. scabies observed in the presence of both compounds was investigated. Physicochemical properties of membranes could, indeed, influence the activity of membrane-embedded enzymes (29). Thus, modification of membrane properties attributable to the presence of suberin could theoretically enhance cellobiose uptake. However, no detectable difference in cellobiose entry was observed between bacteria exposed or not to suberin, indicating that suberindeprived bacteria were not limited in cellobiose uptake.

On the other hand, suberin appeared to affect expression of at least some of the genes involved in cellobiose catabolism. The transporter genes (permeases) of cluster III and the cellobiase-like gene located in their vicinity were of particular interest. Genes responsible for virulence in pathogenic Streptomyces spp. are clustered on a pathogenicity island (PAI) (14). These four genes are located between two virulence genes of the PAI (necl and tomA, encoding a necrosis protein and a tomatinase, respectively) and are consequently directly embedded in the PAI. Nevertheless, these genes were not upregulated in the presence of suberin or cellobiose alone or in combination. In contrast, the cellobiose transporter-like and cellobiase-like genes located outside the PAI were upregulated in cellobiose treatments and the expression of these genes was even more pronounced in the presence of both suberin and cellobiose. In a previous study based on the comparison of the proteomic profiles of S. scabies grown in MSM or in starch and suberin medium, the presence of suberin induced the production of enzymes involved in the energy metabolism of the bacteria, even if biomass production was similar in both media (18). The three enzymes associated with glycolysis-glyceraldehyde-3-phosphate dehydrogenase, fructose-bis-phosphate aldolase, and triose-phosphate isomerase-that were upregulated in the presence of suberin might have contributed to an increased biomass production.

Thaxtomin A production in $S$. scabies correlated with the expression of the nos and $t x t A$ genes. These genes were shown to be involved in the synthesis of the toxin thaxtomin $(10,15)$. The fact that the expression of the nos and txtA genes was not or slightly induced in the cellobiose treatment suggests that other signals are required for the expression of thaxtomins biosynthetic genes. Thus, suberin might contain the complementary signals required to trigger thaxtomin production. Suberin is a complex biopolymer and the list of its components is not exhaustive. It has been established that $S$. scabies can excrete extracellular proteins with esterase activity that are likely involved in suberin degradation $(21,26)$. The involvement of one or several components of suberin as co-inducers of the thaxtomin biosynthetic genes cannot be discarded. Therefore, several molecules known as suberin components were tested for the induction of thaxtomin synthesis in S. scabies EF-35 grown in the presence of cellobiose but none of them improved thaxtomins production in a significant manner.

In streptomycetes, the onset of secondary metabolism and morphogenesis are often linked (25). Several mutants that failed to produce aerial hyphae were also deficient in antibiotic biosynthesis (3). Although cellobiose is the natural inducer of the major genes responsible for thaxtomin A biosynthesis (13), its presence at concentrations $>0.1 \%$ blocked $S$. scabies in its vegetative phase (Fig. 4). In the natural environment, streptomycetes rely primarily on polymers such as cellulose and chitin for growth. Consequently, these polysaccharides may play a critical role in monitoring the global nutritional status of these microorganisms (5). For instance, it was shown that $\mathrm{N}$-acetylglucosamine, the degradation product of chitin, locked $S$. coelicolor in its vegetative growth phase and, therefore, acted as a critical signal to the developmental program (24). Cellobiose, as a product of cellulose degradation, might play a similar role in $S$. scabies.

Thus, by impeding morphogenesis, cellobiose could indirectly prevent thaxtomin production. This blocking effect of cellobiose could not be overcome by the presence of starch. Although starch alone led to colonies with aerial growth, bald colonies were observed when these substrates were combined. Conversely, suberin, a polymer found on the surface of potato tubers, appeared to unlock, at least partly, the vegetative phase caused by cellobiose because its presence induced sporulation even in the presence of cellobiose. Thus, the high level of transcription of thaxtomins biosynthetic genes in the presence of both suberin and cellobiose might be a result of the combined action of suberin as a
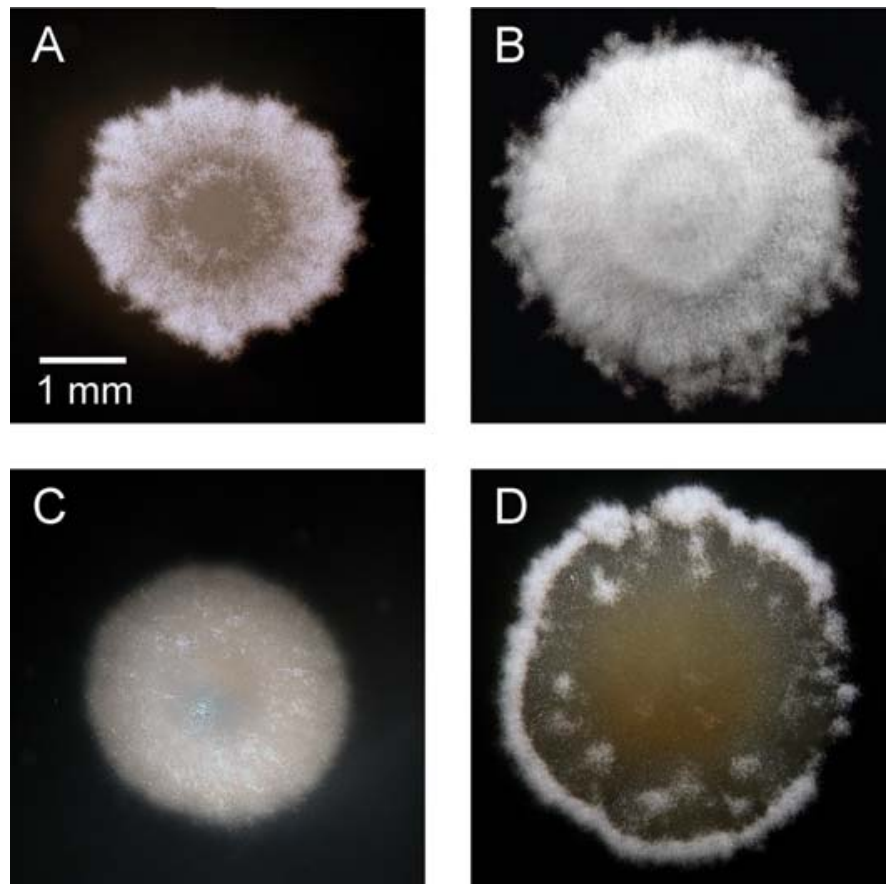

Fig. 4. Morphology of Streptomyces scabies EF-35 colonies after 5 days of growth on solid medium at $30^{\circ} \mathrm{C}$. Growth media tested were A, minimal starch medium (control medium) and control medium supplemented with $\mathbf{B}$, $0.1 \%$ suberin; $\mathbf{C}, 0.5 \%$ cellobiose; or $\mathbf{D}$, suberin + cellobiose. Aerial growth appears as white hyphae in A, B, and D. Colonies shown are representative of the general pattern observed for each treatment. 
strong signal molecule for morphogenesis and of cellobiose as the inducer of the thaxtomin genes.

\section{ACKNOWLEDGMENTS}

This work was supported by the National Sciences and Engineering Research Council of Canada and the Fonds Québécois de Recherche en Nature et Technologie to C. Beaulieu. We thank M. Zitouni for technical assistance.

\section{LITERATURE CITED}

1. Beauséjour, J., Goyer, C., Vachon, J., and Beaulieu, C. 1999. Production of thaxtomin A by Streptomyces scabies strains in plant extract containing media. Can. J. Microbiol. 45:764-768.

2. Bernards, M. A. 2002. Demystifying suberin. Can. J. Bot. 80:227-240.

3. Bibb, M. J. 2005. Regulation of secondary metabolites in streptomycetes. Curr. Opin. Microbiol. 8:208-215.

4. Chakraburtty, R., and Bibb, M. 1997. The ppGpp synthetase gene (relA) of Streptomyces coelicolor A3(2) plays a conditional role in antibiotic production and morphological differentiation. J. Bacteriol. 179:58545861.

5. Colson, S., van Wezel, G. P., Craig, M., Noens, E. E. E., Nothaft, H., Mommaas, A. M., Titgemeyer, F., Joris, B., and Rigali, S. 2008. The chitobiose-binding protein, DasA, acts as a link between chitin utilization and morphogenesis in Streptomyces coelicolor. Microbiology 154:373382.

6. Douliez, J.-P. 2004. Cutin and suberin monomers are membrane perturbants. J. Colloid Interface Sci. 271:507-510.

7. Faucher, E., Savard, T., and Beaulieu, C. 1992. Characterization of actinomycetes isolated from common scab lesions on potato tubers. Can. J. Plant Pathol. 14:197-202.

8. Goyer, C., and Beaulieu, C. 1997. Host range of streptomycete strains causing common scab. Plant Dis. 81:901-904.

9. Goyer, C., Vachon, J., and Beaulieu, C. 1998. Pathogenicity of Streptomyces scabies mutants altered in thaxtomin A production. Phytopathology 88:442-445.

10. Healy, F. G., Wach, M., Krasnoff, S. B., Gibson, D. M., and Loria, R. 2000. The txtAB genes of the plant pathogen Streptomyces acidiscabies encode a peptide synthetase required for phytotoxin thaxtomin A production and pathogenicity. Mol. Microbiol. 38:794-804.

11. Hill, J., and Lazarovits, G. 2005. A mail survey of growers to estimate potato common scab prevalence and economic loss in Canada. Can. J. Plant Pathol. 27:46-52.

12. Johnson, E. G., Joshi, M. V., Gibson, D. M., and Loria, R. 2007. Cellooligosaccharides released from host plants induce pathogenicity in scabcausing Streptomyces species. Physiol. Mol. Plant Pathol. 71:18-25.

13. Joshi, M. V., Bignell, D. R. D., Johnson, E. G., Sparks, J. P., Gibson, D. M., and Loria, R. 2007. The AraC/XylS regulator TxtR modulates thaxtomin biosynthesis and virulence in Streptomyces scabies. Mol. Microbiol. 66:633-642.

14. Kers, J. A., Cameron, K. D., Joshi, M. V., Bukhalid, R. A., Morello, J. E.,
Wach, M. J., Gibson, D. M., and Loria, R. 2005. A large, mobile pathogenicity island confers plant pathogenicity on Streptomyces species. Mol. Microbiol. 55:1025-1033.

15. Kers, J. A., Wach, M. J., Krasnoff, S. B., Widom, J., Cameron, K. D., Bukhalid, R. A., Gibson, D. M., Crane, B. R., and Loria, R. 2004 Nitration of a peptide phytotoxin by bacterial nitric oxide synthase. Nature 429:79-82.

16. King, R. R., and Lawrence, C. H. 1996. Characterization of new thaxtomin A analogues generated in vitro by Streptomyces scabies. J. Agric. Food Chem. 44:1108-1110.

17. Kolattukudy, P. E., and Agrawal, V. P. 1974. Structure and composition of aliphatic constituents of potato tuber skin (suberin). Lipids 9:682-691.

18. Lauzier, A., Simao-Beaunoir, A.-M., Bourassa, S., Poirier, G. G., Talbot, B., and Beaulieu, C. 2008. Effect of potato suberin on Streptomyces scabies proteome. Mol. Plant Pathol. 9:753-762.

19. Lawrence, C. H., Clark, M. C., and King, R. R. 1990. Induction of common scab symptoms in aseptically cultured potato tubers by the vivotoxin, thaxtomin. Phytopathology 80:606-608.

20. Lever, M. 1972. A new reaction for colorimetric determination of carbohydrates. Anal. Biochem. 47:273-279.

21. McQueen, D. A. R., and Schottel, J. L. 1987. Purification and characterization of a novel extracellular esterase from pathogenic Streptomyces scabies that is inducible by zinc. J. Bacteriol. 169:1967-1971.

22. Nodwell, J. R., McGovern, K., and Losick, R. 1996. An oligopeptide permease responsible for the import of an extracellular signal governing aerial mycelium formation in Streptomyces coelicolor. Mol. Microbiol. 22:881-893.

23. Pfaffl, M. W. 2001. A new mathematical model for relative quantification in real-time RT-PCR. Nucleic Acids Res. 29:2002-2007.

24. Rigali, S., Nothaft, H., Noens, E. E. E., Schlicht, M., Colson, S., Müller, M., Joris, B., Koerten, H. K., Hopwood, D. A., Titgemeyer, F., and van Wezel, G. P. 2006. The sugar phosphotranferase system of Streptomyces coelicolor is regulated by the GntR-family regulator DasR and links $N$ acetylglucosamine metabolism to the control of development. Mol. Microbiol. 61:1237-1251.

25. Rigali, S., Titgemeyer, F., Barends, S., Mulder, S., Thomae, A. W., Hopwood, D. A., and van Wezel, G. P. 2008. Feast or famine: the global regulator DasR links nutrient stress to antibiotic production by Streptomyces. EMBO Rep. 9:670-675.

26. Schottel, J. L., Hale, V., and Babcock, M. J. 1992. Regulation and secretion of an extracellular esterase from Streptomyces scabies. Gene 115:27-31.

27. Sprusansky, O., Stirrett, K., Skinner, D., Denoya, C., and Westpheling, J. 2005. The bkdR gene of Streptomyces coelicolor is required for morphogenesis and antibiotic production and encodes a transcriptional regulator of a branched-chain amino acid dehydrogenase complex. J. Bacteriol. 187:664-671.

28. Wach, M. J., Krasnoff, S. B., Loria, R., and Gibson, D. M. 2007. Effect of carbohydrates on the production of thaxtomin A by Streptomyces acidiscabies. Arch. Microbiol. 188:81-88.

29. Weber, F. J., and de Bont, J. A. M. 1996. Adaptation mechanisms of microorganisms to the toxic effects of organic solvents on membranes. Biochim. Biophys. Acta 1286:225-245. 